\title{
Industry-Level Emission Trading between Power Producers in the EU
}

\author{
Christoph Böhringer*
}

\begin{abstract}
In this paper we investigate how restrictions for emission trading to the energy-intensive power sector will affect the magnitude and distribution of abatement costs across EU countries vis-à-vis a comprehensive EU emission trading regime. We find that emission trading between European power sectors allows the harvest of a major part of the efficiency gains provided by full trade as compared to strictly domestic action. However, trade restrictions may create a more unequal distribution of abatement costs across member states than is the case for a comprehensive trade regime. The reason for this is that restricted permit trade enhances the secondary terms-of-trade benefits to EU member countries with low marginal abatement costs at the expense of the other EU member states.
\end{abstract}

Key words: emission trading, computable general equilibrium

JEL classification: D58, Q43, Q58,

* Centre for European Economic Research (ZEW), P.O. Box 103443, D-68034 Mannheim, Phone: +49 621125 200, Fax: +49 6211235 226, E-mail: boehringer@zew.de 


\section{Introduction}

Under the Kyoto Protocol, the European Union committed itself to reducing its emission of greenhouse gases by $8 \%$ during the period $2008-2012$ as compared to 1990 emission levels. Cost-effectiveness considerations suggest that marginal abatement costs across the different emission sources should be equalized. This could be achieved at the international level by a system of tradable emission permits. However, the scope and institutional design of a tradable permit system is highly disputed among signatory parties of the Kyoto Protocol (see e.g. Oberthür and Ott 1999). Reservations against unrestricted emission trading range from concerns on environmental effectiveness to ethically founded arguments that industrialized countries try " to cheaply buy themselves out". The EU shares some of these reservations but insists at the same time that intra-EU emission trading should be considered as domestic action and not as international emission trading the latter being yet undefined and unapproved under Article 17 of the Kyoto Protocol. The latest European Commission's Green Paper on Greenhouse Gas Emission Trading within the European Union promotes intra-EU emission trading as a key instrument for reaching the aggregate EU target in a cost-effective way (COM 2000). In the run-up of the Kyoto budget period, the EU contemplates on commencing an internal emission trading scheme by 2005 . With respect to the scope of an EU emission trading system, the EU considers starting with a relatively small number of economic sectors that contribute significantly to total emissions and exhibit larger differences in marginal abatement costs. 
In this context, we analyze the economic implications of industry-level emission trading within the EU. The prime candidate for restricted industry-level trading is the electricity sector which - according to the most recent Business-as-Usual (BaU) projections (EiE 1999) - will continue to account for roughly a third of the overall EU carbon emissions and more than $70 \%$ of the industry's total emissions. We compare the magnitude and distribution of efficiency gains from permit trading across EU electricity sectors with the no-trade case in which EU member countries meet their Kyoto targets through strictly domestic action. In addition, we supplement information about the extent to which EUwide industry-level emission trading within the electricity sector reduces potential efficiency gains that accrue from full trade of emission permits within the EU. As to industry-level emission trading we distinguish two sub-cases. One, in which emission rights are handed out for free to the power producers in their countries, and one, in which permits are auctioned to the power producers by the respective governments.

The key insights from our analysis can be summarized as follows:

(i) Emission trading at the level of the European power industry, where permits are auctioned by the respective governments, reduces EU-wide costs of meeting the Kyoto targets through strictly domestic action by about $20 \%$. This corresponds to roughly half of the cost savings achievable through a comprehensive permit trading system.

(ii) Grandfathering permits instead of auctioning them has important efficiency implications. When permits are given away to power producers at no charge on the condition that the additional income is used to support production, efficiency gains from 
industrial permit trade nearly vanish. The reason for this is that grandfathered permits work as distortionary subsidies on the output side. Grandfathered permits yield the smallest adverse effects on the electricity sectors, with power generation exceeding even $B a U$ levels for most countries. The latter could provide an incentive for the European power industry to act as a first mover on the basis of grandfathered permits.

(iii) While all other EU member states face welfare losses, Austria, France, and Germany benefit from emission constraints under the Kyoto Protocol. As these countries have relatively low effective reduction targets, they gain competitiveness over other EU countries that face much higher emission constraints: The implied change in the terms of trade more than offsets their domestic abatement costs.

(iv) Full trade in permit rights does not provide a Pareto-improvement as compared to the no-trade case. Austria, France, and Germany suffer from terms-of-trade losses when abatement costs get equalized across regions which dominate their primary gains from emission sales. On the other hand, restricted emission trading across EU power sectors makes Austria, Germany, and France better off than they would be in the no-trade case: EU-wide trade in the electricity sector still leaves huge differentials in the marginal abatement costs of the non-electric sectors across EU countries. Austria, France, and Germany, then, further experience gains in competitiveness, i.e. secondary terms-of-trade benefits, while making additional income from sales of permits on the electricity market.

Our insights emerge from numerical simulations with a large-scale CGE model for the world economy. The model developed not only incorporates all EU member countries, but 
also other Annex-B parties as well as major non-Annex-B regions. With its regional disaggregation outside the EU, the model accounts for important changes on international prices and trade flows triggered by the emission abatement of Annex-B parties outside the EU. Apart from the detailed regional breakdown of the EU, another novelty of our model is the incorporation of most recent information on future trends of the energy systems and economic growth for individual EU countries based on comprehensive research undertaken by the European Commission (EiE 1999).

Our analysis complements a recent study commissioned by the EU on the economic effects of alternative trading schemes (Capros and Mantzos 2000). This study - based on a partial equilibrium bottom-up model for the European energy system - identifies a similar order of magnitude for the EU-wide costs of complying with the Kyoto targets under alternative trading regimes. However, our results differ significantly from Capros and Mantzos with respect to the distributional consequences of emission trading. The partial equilibrium approach does not account for income effects due to shifts in the terms of trade, which may account for a larger part of the total economic effect a country faces from multilateral carbon abatement policies. Moreover, we show that alternative ways of recycling permit rents may have important implications on the economy-wide efficiency of abatement strategies.

The remainder of the paper is as follows. In section 2 we give a brief model summary, motivate the importance of the $B a U$ calibration, and describe the steps involved in the 
parameterization of our analytical framework. In section 3 we present our scenarios and interpret the computational results. In section 4 we summarize.

\section{Analytical Model and Baseline Calibration}

For our analysis, we use a general equilibrium model of the world economy featuring 7 sectors ( 5 of which are energy sectors) and 23 regions (15 of which are EU member states). The choice of sectors captures key dimensions in the analysis of carbon abatement such as differences in carbon intensities and the scope for substitutability across energy goods and carbon-intensive non-energy goods. The regional aggregation covers the Annex-B parties as well as major non-Annex-B regions which are central to the greenhouse gas issue. Table 1 summarizes the sectors and regions incorporated in the model.

The functional forms and key model assumptions are standard within the CGE approach to carbon abatement policy analysis (see e.g. Böhringer 2000). A detailed algebraic summary of the generic model is given in the Appendix.

The costs of complying with Kyoto depend crucially on the extent to which the emission reduction commitments bind economies in the budget period between 2008 and 2012. The expected magnitude of abatement costs is directly linked to the structural characteristics of each particular economy exhibited in the $B a U$ situation without exogenous emission constraints. For example, higher economic growth in the baseline will - ceteris paribus result in increased $\mathrm{BaU}$ emissions that imply higher compliance costs with the Kyoto targets. On the other hand, energy efficiency improvements allow decoupling economic 
growth from emission increase. The specific differences in economic development may either reduce or enlarge the cross-country differences with respect to the effective reduction requirement under the Kyoto Protocol. These differences are an important determinant for the shifts in comparative advantage, which translate into secondary burdens or benefits from carbon abatement via changes in international prices (terms-oftrade effects).

To summarize, $B a U$ projections have a major influence on the magnitude and distribution of abatement costs and hence deserve careful analysis when real policy conclusions should be drawn.

For the baseline parametrization of our model, we have harmonized most recent economic and energy flow information from different sources. The first step has been the construction of a consistent benchmark data set for the year 1995 using:

- GTAP4 (McDougall, Elbehri, and Truong, 1998): GTAP currently includes inputoutput tables for 50 sectors in 45 regions with bilateral trade flows for 1995.

- EUROSTAT (Beutel 1999): EUROSTAT provides input-output tables with 25 sectors for all EU member countries in 1995.

- IEA energy balances and energy prices/taxes (IEA 1999): IEA reports physical energy flows and energy prices for industrial and household demands in a time series until1998. 
- CHELEM (WEFA 1998): The CHELEM database supplies harmonized accounts on bilateral trade between countries.

A shortcoming of GTAP4, with respect to EU policy analysis, is the missing full disaggregation of the European Union (GTAP4 explicitly represents Germany, Denmark, Sweden, Finland and the United Kingdom - all other EU member countries are summarized in an aggregate Rest of EU). We employ EUROSTAT and CHELEM in order to disaggregate the composite EU region within GTAP, so that we ultimately have all individual EU countries represented. The IEA data is used twofold in the construction of the benchmark data set: (i) EUROSTAT has summarized all energy translated transactions within one single energy branch. However, the analysis of carbon abatement policies requires the representation of alternative energy carriers. Based on physical energy flows and respective energy prices, we split down the aggregate EUROSTAT energy sector into five subsectors: COL, GAS, CRU, OIL, and ELE; (ii) we do a "bottom-up" calibration of energy demands and supplies for the updated GTAP dataset in order to obtain sectorspecific and energy-specific emission coefficients. Finally, we use the reconciliated benchmark data for 1995 to calibrate parameters of the CES functional forms from a given set of quantities and prices.

The second step of the parametrization involves a forward calibration of the 1995 economies to the year 2010. Here, we incorporate exogenous information from two sources: 
- DOE (Department of Energy 1999): The U.S. Department of Energy gives information on GDP growth, energy demand, energy supply, and future energy prices for various countries and world regions.

- EiE (Energy in Europe 1999): EiE provides detailed information on the future development of the European energy system and economic growth for all individual EU member states.

We replace the DOE projections which are given only for the whole of Europe with the detailed baselines at the member state level as given in EiE. The model is then calibrated to exogenous information on non-uniform growth rates in GDP, fossil fuel production, fuel mixes in electricity generation, changes in world market energy prices, and $\mathrm{CO}_{2}$ emission profiles (see Böhringer, Jensen and Rutherford 2000 for a detailed description of related calibration techniques). AEEI ${ }^{1}$ factors are used to match energy demands by consumers and production activities to fossil fuel supplies, i.e. carbon emission projections. It should be noted, that the prospects for decoupling economic growth and carbon emissions for the European Union are on average much more optimistic in the EiE perspective than in the DOE view. Despite of lower average GDP growth rates between 1995 and 2010 (2.2\% per year (DOE) versus $2.5 \%$ per year (EiE)) DOE projects significantly higher carbon emissions for the whole of the $\mathrm{EU}$ (3.75 billion tons of $\mathrm{CO}_{2}$ as compared to 3.3 billion tons

${ }^{1}$ Autonomous energy efficiency improvement is due to autonomous technical progress in addition to energy demand reductions that are caused by increases in energy prices. 
by $\mathrm{EiE}$ ). The EiE assumptions on fuel re-shifting towards renewables and large efficiency improvements account for these differences.

Table 2 provides a summary of historic and future aggregate carbon emissions across countries to which the model has been calibrated. The emission projections in 2010 yield the effective reduction requirements individual parties face under the Kyoto requirement. Given the uncertainty surrounding the evolution of non- $\mathrm{CO}_{2}$ greenhouse gas emissions, we assume implementation of the six-gas burden sharing agreement for $\mathrm{CO}_{2}$ only.

The effective reduction requirements across Annex B countries in 2010 are very different from the nominal Kyoto commitments based on 1990 emission levels. For example, the USA, which committed itself to a 7\% reduction target with respect to the 1990 level, faces an effective cutback requirement of nearly $30 \%$ as compared to the $2010 \mathrm{BaU}$ level. On the other hand, regions like EIT and FSU will stay well below their 1990 emission levels due to structural breaks in economic activities. As to the European Union, the aggregate nominal EU target of $8.6 \%$ comes down to an effective target of $14.2 \%$.

Apart from matching the model at the regional level to the emission projections provided in Table 2, we also calibrate functional forms for power production, i. e. the energy mix in electricity generation, to reproduce the $B a U$ emissions from power generations in 2010 according to the specific EiE forecasts (EiE 1999, pp. 188-217). The latter calibration provides us with the energy experts' starting point for analyzing the implications of EUwide carbon emission trading across the electricity sectors. Table 3 summarizes the 
projected demands of fossil fuels and the implicit carbon emissions to which our model has been calibrated under $\mathrm{BaU}$.

\section{Policy Scenarios and Numerical Results}

\subsection{Policy Scenarios}

In our numerical simulations we distinguish four scenarios. We start with a scenario NTR in which all Annex-B countries meet their Kyoto targets through domestic action only: The governments set domestic emission taxes sufficiently high to meet the national reduction targets. $^{2}$ The NTR simulation delivers a benchmark for the magnitude and distribution of efficiency gains emerging from cross-country flexibility of emission abatement within the EU. The natural counterpart to the $N T R$ case is the scenario $T R D$, in which emission permits can be traded across all sectors and EU member states: Equalization of marginal abatement costs across all emission sources implies a cost-efficient solution with respect to the overall EU reduction target, if we abstract from transaction costs and the possibility of extra-EU emission trading. We can then measure to what extent the EU forgoes potential

${ }^{2}$ Likewise, the government could auction emission permits within domestic borders, aligning the total amount of auctioned permits with its domestic Kyoto emission reduction target. 
efficiency gains from restricting intra-EU permit trade to the electricity sector. ${ }^{3}$ Restriction of emission trading to some sectors poses the question of how many emission rights should be allocated to these sectors. For our simulations of emission trading across EU electricity sectors, we adopt the following rule: Each EU country splits up its emission endowments given by the EU burden sharing agreement according to the reduction of emissions in the NTR case. $^{4}$ In other words: the national government sets aside emission rights for the electricity sector which are equal to the emissions generated by power producers in the $N T R$ case. Industry-level emission trading allows the EU power industry to identify the least-cost emission abatement solution within the European electricity sector. At the same time, each national government must assure that the other sectors in the economy do not overuse the remaining emission rights (i.e. the Kyoto entitlements reduced by the permits allocated to the electricity sector). In our simulations, all other non-electric sectors in the economy are subject to a carbon tax which is set sufficiently high to keep with the remaining emission budget. With respect to electricity-level emission trading, we distinguish two cases: The scenario $E L E \_A P$ reflects a setting in which the government auctions permits to the power industry; the scenario ELE_GP considers a setting where

${ }^{3}$ Under implementation considerations, the excess costs of restricting trade provides an upper bound for the transaction costs that arise from an extension of the permit trading system.

${ }^{4}$ Note that the allocation of emissions in the NTR case represents an efficient outcome if only domestic action is permissible. 
emission rights are given away at no charge to the electricity sector (grandfathering). Throughout the simulations, we assume that revenues from the application of carbon taxes or the introduction of emission permits are recycled lump-sum to the representative consumer. The one exception - as just noted - is the scenario ELE_GP, in which some fixed amount of emission rights are handed out for free to the power sector. Table 4 summarizes the main characteristics of the abatement scenarios described above.

\subsection{Results}

Table 5 summarizes the welfare effects across the alternative emission abatement scenarios reduction that are measured as percentage changes in real consumption in comparison to the baseline. These relative changes are translated in total compliance costs in billions of $\mathrm{ECU}_{95}$ as given in Table 6. Table 7 indicates the marginal abatement costs for the different scenarios, and Table 8 reports the quantities of traded emissions for the respective scenarios. Note that the label EUR is used in the tables below to denote the economic effects at the aggregate EU level (see also Table 1), whereas the label OTH subsumes all non-EU regions.

Our interpretation of results starts with the no-trade case NTR in which Annex-B countries impose domestic carbon taxes which are sufficiently high in order to meet their respective Kyoto target. Not surprisingly, those regions (EUR, USA, JPN, OOE) that face a binding emission constraint in 2010 bear adjustment costs towards less carbon-intensive consumption and production patterns. Among OECD countries, the EU faces by far the 
lowest costs. The main reason is that - based on our official projections - its effective aggregate reduction requirement is much lower than those of USA, JPN and OOE.

Carbon abatement in large open economies may produce substantial spillovers on trading countries due to the implied changes in international prices, particularly on world markets for fossil fuels. We can directly monitor these spillovers for regions that do not have to implement abatement measures. ${ }^{5}$ Among Annex-B regions, EIT and FSU have abundant carbon emission rights, but they are nevertheless affected in different ways by abatement in the OECD countries. While EIT faces a secondary benefit, FSU suffers from a secondary loss. The primary explanation is that EIT, as a large fuel importer, benefits from falling world market prices of fuels (as a consequence of decreased world demand) whereas FSU, as a fuel exporter, faces a revenue loss. The same reasoning applies for fuel exporting MPC. The terms-of-trade effects on fossil fuel markets may be strengthened or weakened by shifts in comparative advantage on non-fossil fuel markets depending on a country's initial trade relations and the effective carbon tax. ROW, e.g., will suffer income losses with respect to its fossil fuel exports. However, these losses are more than offset by additional income from increased world market shares in trade of non-energy goods associated with its energy cost advantage as compared to OECD countries.

5 For a straightforward decomposition of the total general equilibrium effect into a domestic market effect keeping international prices constant and an international market effect that accounts for terms-of-trade effects see Böhringer and Rutherford 1999. 
When we focus on the economic implications at the EU country level, we observe that some countries may gain rather than lose from carbon abatement. Again, the differences in reduction requirements and terms-of-trade effects account for this result: Due to low effective reduction targets, AUT, DEU, and FRA face low marginal abatement costs. As compared to other EU trading partners they can levy much lower carbon taxes and therefore experience a cost advantage in energy-intensive production. Table 9 illustrates the induced shift in comparative advantage for energy-intensive goods. While average EU production in energy-intensive goods declines, AUT, DEU, and FRA, significantly increase their production.

The cost advantage for low tax countries AUT, DEU, and FRA, more than offsets their costs from domestic emission abatement. DNK, FIN, GRC, NET, and PRT, at the other end, face rather high effective reduction targets accompanied by substantial adjustment costs.

Full emission trading within the EU bubble cuts down compliance costs by nearly $40 \%$, while the spillovers of this regime change outside the EU are negligible. Permit trade within the EU has important implications not only for the total costs of EU abatement, but also for the implied changes in the distribution of costs as compared to the NTR case. First of all, the range in burden across EU countries shrink. In other words: The allocation of efficiency gains via the market supports a more "equitable" outcome in terms of percentage welfare loss (see Table 5). Countries like DNK, FIN, GRC, IRE, PRT, IRE, and NET can significantly reduce their compliance costs by buying cheaper abatement from abroad. Due 
to terms-of-trade effects, not all countries will necessarily gain from permit trade. In fact, AUT, DEU, and FRA suffer from a terms-of-trade loss as compared to NTR. Their gains in competitiveness with respect to energy-intensive production vanishes with equalized marginal abatement costs across EU countries which is not offset by permit sales.

How will the magnitude and the distribution of abatement costs change when we restrict intra-EU permit trade to the electricity industry? For $E L E \_A P$, where emission permits are auctioned by the respective governments to the power sector, the aggregate efficiency gains as compared to the full-trade case drop by half. Although this loss appears substantial, one could argue that emission trading between EU power generators only brings in $50 \%$ of the efficiency gains from unrestricted permit trade. From an implementing point of view, the extension of permit trade to sectors where the operation of a permit system can become much more costly does not warrant large additional economic gains. Another interesting result is that AUT, DEU, and FRA actually would prefer restricted trade between power producers over both the full-trade scenario TRD and the notrade scenario NTR. The reasoning behind this is that trade across the EU power industry still provides significant differences in marginal abatement costs for the non-electric sectors such that AUT, DEU, and FRA further experience gains in comparative advantage due to their low abatement costs (as compared to TRD) and make additional income from permit sales in the European electricity market (as compared to NTR). The terms-of-trade gains for AUT, DEU, and FRA work at the expense of the other EU countries whose welfare gains from full trade are substantially reduced under ELE-AP. 
If the national governments give away permits to the power sector rather than selling them, the aggregate EU efficiency gains fall close to zero as power producers use the additional income to lower electricity prices and mitigate adverse adjustment effects of carbon abatement on power production. Grandfathered permits, then, work as implicit output subsidies which cause efficiency losses due to the implied distortions in the allocation of production resources (see Böhringer, Ferris and Rutherford 1998). As can be seen from Table 10, grandfathering further reduces negative effects on power production and even implies significant positive output changes as compared to the baseline for various EU countries. While grandfathering can not be defended on efficiency grounds, it significantly reduces the dispersion of production changes in power industries across the EU countries.

Finally, note that there is an important interaction between the distribution of permit rents and the permit price itself. Implicit subsidies to the power producers under ELE_GP lead to lower relative prices for emission-intensive electricity generation which, in turn, creates higher demands and higher permit prices (see Table 7 for the associated difference in equalized marginal abatement costs between $E L E \_A P$ and $\left.E L E \_G P\right)$.

\section{Conclusions}

In wake of the forthcoming Kyoto budget period 2008-2012, the EU is contemplating commencement of an emission trading scheme within the Community by 2005 . One major question to be resolved is the sectoral scope of an intra-EU emission trading system. Considering that transaction costs of an emission trading system may quickly increase with 
the number of economic sectors involved, a reasonable approach is to include only a small number of sectors that contribute significantly to total emissions and exhibit larger differences in marginal abatement costs.

In this paper, we have analyzed the economic implications of restricting emission trading to the EU power sectors as compared to unrestricted trade as well as strictly domestic action. We find that industry-level emission trading among EU power producers already yields a large share of potential efficiency gains from full trade. However, this results only holds if permits are auctioned to the electricity sector and not given away for free. In the latter case, the gains from equalization of marginal abatement costs across power producers get absorbed up from economy-wide efficiency losses due to the implicit subsidies for the electricity sectors.

With respect to cost distribution, the transition from purely domestic action to a comprehensive trading system does not provide a Pareto-improvement because countries with low marginal abatement costs may lose initial cost advantages (terms-of-trade gains) under the no-trade case that are not offset by additional income from permit sales. On the other hand, comprehensive trade reduces the dispersion of welfare costs across EU countries which may be interpreted as a shift towards more "equitable" burden sharing. Restriction of permit trade which may be defeated on transaction costs grounds can run cross equity considerations as it accentuates the relative gains for low tax countries even more at the expense of other countries. 


\section{References}

Armington, P.S. (1969) A Theory of Demand for Products Distinguished by Place of Production, IMF Staff Papers 16, pp. 159-178.

Beutel, J. (1999) Report to the Statistical Office of the European Communities, EUROSTAT.

Böhringer, C.; Ferris, M.; Rutherford, T.F. (1998) Alternative $\mathrm{CO}_{2}$ abatement strategies for the European Union, in Climate change, transport and environmental policy (Eds.) J. Braden and S.Proost, Edgar Elgar Publishing, pp.16-47.

Böhringer, C. (2000) Cooling Down Hot Air: A Global CGE Analysis of Post-Kyoto Carbon Abatement Strategies, Energy Policy 28 (2000), pp.779-789.

Böhringer, C.; Rutherford, T.F. (2000) World Economic Impacts of the Kyoto Protocol, in Internalization of the Economy, Environmental Problems and New Policy Options (Eds.) Welfens, P.J.J, Hillebrand, R., Ulph. A., Springer (forthcoming).

Böhringer, C.; Jensen, J.; Rutherford, T.F. (2000) Energy Market Projections and Differentiated Carbon Abatement in the European Union, in Efficiency and Equity of Climate Change Policy (Ed.) C. Carraro, Kluwer.

Capros, P.; Mantzos, L. (2000) The Economic Effects of EU-Wide Industry-Level Emission Trading to Reduce Greenhouse Gases, ICCS, National Technical University of Athens.

COM (2000) Green Paper on Greenhouse Gas Emission Trading within the European Union, COM 2000/87, European Commission, Bruxelles. 
DOE (1999) Annual Energy Outlook (AEO 1999)', Department of Energy, Energy Information Administration, http://www.eia.doe.gov.

EiE (1999) European Union Energy Outlook to 2020, Energy in Europe, European Commission, Bruxelles.

IEA (1999) Energy Prices and Taxes / Energy Balances of OECD and Non-OECD countries, International Energy Agency, IEA publications, Paris http://www.iea.org/stat.htm.

McDougall, R.A.; A. Elbehri; Truong, T.P. (1998) Global Trade Assistance and Protection: The GTAP 4 Data Base, Center for Global Trade Analysis, Purdue University.

Oberthür, S.; Ott, H.E. (1999) The Kyoto Protocol, Springer, Berlin.

UNFCCC (1997) Kyoto Protocol to the United Nations Framework Convention on Climate Change, United Nations Convention on Climate Change, FCCC/CP/L.7/Add1, Kyoto.

WEFA (1998) Comptés Harmonisés sur les Echange et L'Economie Mondiale, Paris. 
Table 1: Overview of sectors and countries/regions

\begin{tabular}{|c|c|c|c|}
\hline \multicolumn{2}{|c|}{ Sectors } & \multicolumn{2}{|c|}{ Regions } \\
\hline $\begin{array}{l}\text { COL } \\
\text { CRU } \\
\text { GAS } \\
\text { OIL } \\
\text { ELE }\end{array}$ & $\begin{array}{l}\text { Coal } \\
\text { Crude oil } \\
\text { Natural gas } \\
\text { Refined oil products } \\
\text { Electricity }\end{array}$ & EUR & $\begin{array}{l}\text { European Union: AUT-Austria, BEL- } \\
\text { Belgium, DEU-Germany, DNK-Denmark, } \\
\text { FIN-Finland, FRA-France GRC-Greece, } \\
\text { GBR-United Kingdom, IRE-Ireland, ITA- } \\
\text { Italy, LUX-Luxemburg, NET-Netherlands, } \\
\text { PRT-Portugal, SPN-Spain, SWE-Sweden }\end{array}$ \\
\hline EIS & Energy-intensive sectors & $\mathrm{CIN}$ & China and India \\
\hline \multirow[t]{7}{*}{ Y } & Manufactures and services & EIT & Economies in Transition \\
\hline & & FSU & Former Soviet Union \\
\hline & & MPC & Mexico and OPEC \\
\hline & & OOE & $\begin{array}{l}\text { Other OECD (Australia, Canada and New } \\
\text { Zealand) }\end{array}$ \\
\hline & & JPN & Japan \\
\hline & & ROW & Rest of World \\
\hline & & USA & United States \\
\hline
\end{tabular}


Table 2: Carbon emissions and reduction requirements (EiE 1999)

\begin{tabular}{|c|c|c|c|c|}
\hline & \multicolumn{2}{|c|}{ Carbon emissions in million tons $\mathrm{CO}_{2}$} & \multicolumn{2}{|c|}{ Reduction requirements in $\%$} \\
\hline & 1990 & 2010 & Nominal wrt 1990 & Effective wrt 2010 \\
\hline EUR & 3097.3 & 3299.4 & 8.6 & 14.2 \\
\hline AUT & 56.2 & 54.8 & 13.0 & 10.8 \\
\hline BEL & 104.3 & 124.0 & 7.5 & 22.2 \\
\hline DEU & 948.2 & 827.0 & 21.0 & 9.4 \\
\hline DNK & 50.2 & 54.9 & 21.0 & 27.8 \\
\hline FIN & 53.1 & 73.6 & 0 & 27.9 \\
\hline FRA & 369.8 & 389.5 & 0 & 5.1 \\
\hline GBR & 559.6 & 572.2 & 12.5 & 14.4 \\
\hline GRC & 65.6 & 109.6 & -25.0 & 25.2 \\
\hline IRE & 29.7 & 42.8 & -13.0 & 21.6 \\
\hline ITA & 385.4 & 429.8 & 6.5 & 16.2 \\
\hline LUX & 9.3 & 8.9 & 28.0 & 24.4 \\
\hline NET & 166.1 & 206.7 & 6.0 & 24.5 \\
\hline PRT & 41.8 & 67.1 & -27.0 & 20.9 \\
\hline SPN & 206.6 & 274.4 & -15.0 & 13.4 \\
\hline SWE & 51.3 & 64.0 & -4.0 & 16.6 \\
\hline EIT & 1103.7 & 967.9 & 7.0 & -6.0 \\
\hline FSU & 3707.0 & 2669.3 & 0 & -38.9 \\
\hline JPN & 1004.7 & 1213.7 & 6.0 & 22.2 \\
\hline OOE & 795.7 & 1044.9 & 0.6 & 24.3 \\
\hline USA & 4931.7 & 6541.2 & 7.0 & 29.9 \\
\hline $\mathrm{CIN}$ & 2834.3 & 6753.8 & - & - \\
\hline MPC & 1034.0 & 1660.9 & - & - \\
\hline ROW & 2445.7 & 4773.9 & - & - \\
\hline
\end{tabular}


Table 3: Fossil fuel demands and emissions in the power sector in 2010 (EiE 1999)

\begin{tabular}{lrrrr}
\hline & Coal (in Mtoe) & Gas (in Mtoe) & Oil (in Mtoe) & $\mathrm{CO}_{2}$ (in Mtons) \\
\hline EUR & 137 & 166.5 & 83.6 & 1202.3 \\
\hline AUT & 0.3 & 3.9 & 0.9 & 13.5 \\
BEL & 1.1 & 7.3 & 2.4 & 29.9 \\
DEU & 59 & 24.5 & 14.7 & 343.5 \\
DNK & 4.3 & 2.8 & 1.6 & 28.4 \\
FIN & 7.6 & 2.9 & 1.1 & 40.9 \\
FRA & 4.1 & 10 & 9.5 & 69.4 \\
GBR & 16.7 & 42.6 & 13.8 & 208.3 \\
GRC & 8.9 & 2.9 & 3.8 & 55.6 \\
IRE & 1.8 & 3.3 & 0.8 & 17.6 \\
ITA & 8.9 & 32.9 & 16.4 & 163.7 \\
LUX & & 0.5 & & 1.3 \\
NET & 5 & 16.8 & 6.6 & 78.3 \\
PRT & 4.2 & 4 & 1.6 & 31.1 \\
SPN & 13.6 & 10.1 & 2.2 & 103 \\
SWE & 1.5 & 2.2 & 17.9 \\
\hline
\end{tabular}




\section{Table 4: Overview of scenarios}

\begin{tabular}{|c|c|c|}
\hline Scenario & $\begin{array}{l}\text { Abatement regime applying within } \\
\text { EU-15 }\end{array}$ & $\begin{array}{l}\text { Abatement regime for non-EU Annex-B } \\
\text { regions }\end{array}$ \\
\hline$\overline{\mid N T R}$ & $\begin{array}{l}\text { No trade in emission rights across } \\
\text { EU countries, domestic emission tax }\end{array}$ & \multirow[t]{4}{*}{$\begin{array}{l}\text { Compliance with Kyoto through } \\
\text { domestic emission tax }\end{array}$} \\
\hline TRD & $\begin{array}{l}\text { Full trade of emission permits across } \\
\text { all EU member states, auctioned } \\
\text { permits }\end{array}$ & \\
\hline$E L E \_A P$ & $\begin{array}{l}\text { Electricity-level EU emission } \\
\text { trading together with target- } \\
\text { compatible domestic carbon taxes } \\
\text { for the remaining sectors; auctioned } \\
\text { permits allocated to electricity sector } \\
\text { correspond to the sector's respective } \\
\text { emissions in the no-trade case }\end{array}$ & \\
\hline$E L E \_G P$ & $\begin{array}{l}\text { Electricity-level EU emission } \\
\text { trading together with target- } \\
\text { compatible domestic carbon taxes } \\
\text { for the remaining sectors; } \\
\text { grandfathered permits allocated to } \\
\text { electricity sector correspond to its } \\
\text { respective emissions in the no trade } \\
\text { case }\end{array}$ & \\
\hline
\end{tabular}


Table 5: Welfare costs (\% change in consumption from $\mathrm{BaU}$ )

\begin{tabular}{lcccc}
\hline & NTR & TRD & ELE_AP & ELE_GP \\
\hline EUR & -0.102 & -0.065 & -0.082 & -0.098 \\
\hline AUT & 0.369 & 0.360 & 0.381 & 0.349 \\
BEL & -0.160 & -0.057 & -0.156 & -0.179 \\
DEU & 0.095 & 0.066 & 0.116 & 0.091 \\
DNK & -0.704 & -0.412 & -0.548 & -0.550 \\
FIN & -0.878 & -0.427 & -0.788 & -0.942 \\
FRA & 0.057 & -0.021 & 0.063 & 0.070 \\
GBR & -0.137 & -0.120 & -0.138 & -0.194 \\
GRC & -0.822 & -0.285 & -0.647 & -0.697 \\
IRE & -0.523 & -0.239 & -0.461 & -0.491 \\
ITA & -0.122 & -0.066 & -0.114 & -0.098 \\
LUX & -0.893 & -0.597 & -0.896 & -0.873 \\
NET & -0.970 & -0.515 & -0.888 & -0.904 \\
PRT & -0.458 & -0.169 & -0.411 & -0.377 \\
SPN & -0.084 & -0.097 & -0.089 & -0.061 \\
SWE & -0.396 & -0.378 & -0.404 & -0.430 \\
\hline OTH & -0.459 & -0.458 & -0.458 & -0.457 \\
\hline EIT & 0.435 & 0.432 & 0.429 & 0.425 \\
FSU & -0.250 & -0.261 & -0.242 & -0.245 \\
JPN & -0.339 & -0.340 & -0.340 & -0.340 \\
OOE & -1.019 & -1.012 & -1.014 & -1.012 \\
USA & -0.769 & -0.768 & -0.769 & -0.768 \\
CIN & -0.025 & -0.025 & -0.026 & -0.019 \\
MPC & -0.899 & -0.891 & -0.893 & -0.895 \\
ROW & 0.387 & 0.383 & 0.384 & 0.389 \\
\hline & & & &
\end{tabular}


Table 6: Total compliance costs (in billion ECU95) annually between 2008-2012

\begin{tabular}{|c|c|c|c|c|}
\hline & NTR & TRD & ELE_AP & ELE_GP \\
\hline$E U R$ & 9.5 & 6.0 & 7.7 & 9.1 \\
\hline AUT & -12.2 & -11.9 & -12.6 & -11.6 \\
\hline BEL & 5.7 & 2.0 & 5.5 & 6.3 \\
\hline DEU & -33.0 & -22.9 & -40.2 & -31.6 \\
\hline DNK & 17.5 & 10.2 & 13.6 & 13.7 \\
\hline FIN & 17.3 & 8.4 & 15.5 & 18.5 \\
\hline FRA & -11.3 & 4.3 & -12.5 & -13.8 \\
\hline GBR & 24.5 & 21.6 & 24.8 & 34.7 \\
\hline GRC & 17.1 & 5.9 & 13.4 & 14.5 \\
\hline IRE & 6.1 & 2.8 & 5.4 & 5.7 \\
\hline ITA & 18.9 & 10.3 & 17.6 & 15.1 \\
\hline LUX & 1.3 & 0.9 & 1.3 & 1.3 \\
\hline NET & 42.0 & 22.3 & 38.4 & 39.1 \\
\hline PRT & 9.5 & 3.5 & 8.5 & 7.8 \\
\hline SPN & 7.6 & 8.9 & 8.1 & 5.5 \\
\hline SWE & 12.9 & 12.3 & 13.1 & 14.0 \\
\hline OTH & 109.2 & 109.1 & 109.1 & 108.7 \\
\hline EIT & -26.2 & -26.1 & -25.9 & -25.7 \\
\hline FSU & 17.3 & 18.1 & 16.8 & 17.0 \\
\hline JPN & 187.2 & 187.8 & 187.7 & 187.7 \\
\hline OOE & 248.7 & 246.8 & 247.5 & 247.0 \\
\hline USA & 891.1 & 890.2 & 891.0 & 889.2 \\
\hline $\mathrm{CIN}$ & 5.4 & 5.4 & 5.6 & 4.2 \\
\hline MPC & 293.4 & 290.8 & 291.6 & 292.2 \\
\hline ROW & -188.2 & -186.2 & -186.7 & -189.4 \\
\hline
\end{tabular}


Table 7: Marginal abatment costs in $\mathrm{ECU}_{95}$ per ton of $\mathrm{CO}_{2}$

\begin{tabular}{|c|c|c|c|c|c|c|}
\hline & NTR & TRD & \multicolumn{2}{|c|}{ ELE_AP } & \multicolumn{2}{|c|}{ ELE_GP } \\
\hline & & & $\begin{array}{l}\text { Power } \\
\text { Sector }\end{array}$ & $\begin{array}{r}\text { Rest of } \\
\text { Economy }\end{array}$ & $\begin{array}{l}\text { Power } \\
\text { Sector }\end{array}$ & $\begin{array}{r}\text { Rest of } \\
\text { Economy }\end{array}$ \\
\hline AUT & 41 & 118 & 72 & 44 & 105 & 35 \\
\hline BEL & 163 & 118 & 72 & 162 & 105 & 151 \\
\hline DEU & 71 & 118 & 72 & 80 & 105 & 52 \\
\hline DNK & 355 & 118 & 72 & 228 & 105 & 176 \\
\hline FIN & 346 & 118 & 72 & 289 & 105 & 257 \\
\hline FRAU & 52 & 118 & 72 & 55 & 105 & 45 \\
\hline GBR & 135 & 118 & 72 & 133 & 105 & 109 \\
\hline GRC & 249 & 118 & 72 & 223 & 105 & 193 \\
\hline IRE & 288 & 118 & 72 & 234 & 105 & 194 \\
\hline ITA & 148 & 118 & 72 & 144 & 105 & 117 \\
\hline LUX & 166 & 118 & 72 & 166 & 105 & 162 \\
\hline NET & 234 & 118 & 72 & 222 & 105 & 202 \\
\hline PRT & 187 & 118 & 72 & 183 & 105 & 163 \\
\hline SPN & 115 & 118 & 72 & 115 & 105 & 98 \\
\hline SWE & 134 & 118 & 72 & 132 & 105 & 120 \\
\hline EIT & - & 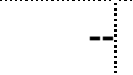 & & - & & - \\
\hline FSU & - & -- & & -- & & -- \\
\hline JPN & 271 & 271 & & 271 & & 270 \\
\hline OOE & 186 & 185 & & 185 & & 184 \\
\hline USA & 283 & 283 & & 283 & & 282 \\
\hline
\end{tabular}


Table 8: Emission exports in million tons of $\mathrm{CO}_{2}$ annually between 2008 and 2012

\begin{tabular}{lrrr}
\hline & TRD & ELE_AP & ELE_GP \\
\hline AUT & 7.0 & 1.4 & 1.5 \\
BEL & -6.3 & -1.2 & -1.1 \\
DEU & 43.7 & 28.1 & 30.1 \\
DNK & -6.0 & -4.7 & -4.7 \\
FIN & -11.8 & -7.3 & -6.8 \\
FRAU & 35.4 & 8.8 & 11.8 \\
GBR & -8.0 & -1.8 & -0.3 \\
GRC & -11.6 & -7.8 & -9.8 \\
IRE & -4.4 & -2.5 & -2.7 \\
ITA & -11.6 & -3.8 & -7.2 \\
LUX & -0.5 & -0.1 & 0.0 \\
NET & -21.8 & -8.6 & -10.4 \\
PRT & -4.8 & -2.3 & -2.6 \\
SPN & 1.4 & 1.9 & 1.5 \\
SWE & -0.8 & -0.1 & 0.7 \\
\hline
\end{tabular}


Table 9: Energy-intensive production (\% change from $\mathrm{BaU}$ )

\begin{tabular}{rrrrr}
\hline & NTR & TRD & ELE_AP & ELE_GP \\
\hline AUT & 7.0 & 1.5 & 4.5 & 3.8 \\
DEU & 5.4 & 2.1 & 3.7 & 3.7 \\
FRA & 6.4 & 2.7 & 5.6 & 3.8 \\
\hline EUR & -4.8 & -2.0 & -3.6 & -2.2 \\
\hline
\end{tabular}


Table 10: Production in electricity sector (\% change from $\mathrm{BaU}$ )

\begin{tabular}{lrrrr}
\hline & NTR & TRD & ELE_AP & ELE_GP \\
\hline AUT & 2.8 & 3.1 & 0.3 & 3.1 \\
BEL & -3.3 & -1.6 & -1.5 & 2.8 \\
DEU & -0.9 & -1.8 & -3.3 & 1.6 \\
DNK & -17.3 & -8.7 & -6.0 & -1.1 \\
FIN & -7.5 & -1.6 & 1.3 & 4.6 \\
FRA & 1.1 & 2.2 & 0.2 & 1.3 \\
GBR & -0.1 & -0.1 & 0.1 & 4.5 \\
GRC & -21.2 & -11.2 & -10.5 & -1.6 \\
IRE & -10.4 & -5.4 & -1.4 & 4.4 \\
ITA & -3.4 & -2.5 & -2.2 & 4.3 \\
LUX & -0.2 & 0.2 & 0.3 & 0.2 \\
NET & -12.9 & -6.2 & -5.2 & 1.7 \\
PRT & -10.7 & -6.6 & -6.6 & 0.2 \\
SPN & -3.5 & -3.7 & -4.2 & 2.2 \\
SWE & 2.4 & 2.1 & 2.3 & 2.6 \\
\hline
\end{tabular}




\section{Appendix A: Algebraic Appendix}

This appendix provides an algebraic summary of the equilibrium conditions for our comparative-static model. The model has been designed to investigate the economic implications of alternative EU emission abatement strategies under the Kyoto Protocol. Before presenting the algebraic exposition we state our main assumptions and introduce the notation.

Nested separable constant elasticity of substitution (CES) functions characterize the use of inputs in production. All production exhibits non-increasing returns to scale. Goods are produced with capital, labor, energy and material (KLEM).

A representative agent in each region is endowed with three primary factors: natural resources (used for fossil fuel production), labor and capital. The representative agent maximizes utility from consumption of an CES composite which combines demands for energy and non-energy commodities. Supplies of labor, capital and natural resources are exogenous. Labor and capital are mobile within domestic borders but cannot move between regions; natural resources are sector specific.

All goods are traded internationally and differentiated by region of origin (Armington 1969). 
Lump sum transfers of the representative agent finance the exogenous government demands in each region and the government transfers all revenues from carbon taxes or auctioned carbon permits to the representative agent.

Two classes of conditions characterize the competitive equilibrium for our model: zero profit conditions and market clearance conditions. The former class determines activity levels and the latter determines price levels. In our algebraic exposition, the notation $\Pi_{i r}^{z}$ is used to denote the profit function of sector $j$ in region $r$ where $z$ is the name assigned to the associated production activity. Differentiating the profit function with respect to input and output prices provides compensated demand and supply coefficients (Shepard's lemma), which subsequently appear in the market clearance conditions. We use $i$ (aliased with $j$ ) as index for commodities (sectors), $r$ (aliased with $s$ ) as index for regions and $d$ as index for the demand category ( $d=Y$ : intermediate demand, $d=C$ : private household demand, $d=G$ : investment demand, $d=I$ : investment demand). The label $E G$ represents the set of energy goods and the label FF denotes the subset of fossil fuels. Tables A.1 - A.6 explain the notations for variables and parameters employed within our algebraic exposition. 


\section{A.1 Zero Profit Conditions}

1. Production of goods except for fossil fuels:

$\Pi_{i r}^{Y}=p_{i r}-\sum_{j \notin E G} \theta_{j i r} p_{Y j r}^{A}-\theta_{i r}^{K L E}\left[\theta_{i r}^{E} p_{i r}^{E l-\sigma_{K L E}}+\left(1-\theta_{i r}^{E}\right)\left(\theta_{i r}^{K L} p l_{r}^{1-\sigma_{K L}}+\left(1-\theta_{i r}^{K L}\right) p k_{r}^{1-\sigma_{K L}}\right)^{\frac{l-\sigma_{K L E}}{I-\sigma_{K L}}}\right]^{\frac{1}{1-\sigma_{K I E}}}=0 \quad \mathrm{i} \notin \mathrm{FF}$

2. Production of fossil fuels:

$\Pi_{i r}^{Y}=p_{i r^{-}}\left[\theta_{i r}^{Q} p q_{i r}^{1-\sigma_{Q}}+\left(1-\theta_{i r}^{Q}\left(\theta_{L i r}^{F F} p l_{r}+\theta_{K i r}^{F F} p k_{r}+\sum_{j} \theta_{j i r}^{F F} p_{Y j r}^{A}\right)^{1-\sigma_{Q}}\right]^{\frac{1}{1-\sigma_{Q}}}=0 \quad i \in \mathrm{FF}\right.$

3. Energy aggregate (except for electricity sector):

$\prod_{i r}^{E}=p_{i r}^{E}-\left\{\theta_{i r}^{E L E} p_{\{Y, E L E, r\}}^{A^{1-\sigma_{E L E}}}+\left(1-\theta_{i r}^{E L E}\right)\left[\theta_{i r}^{C O A} p_{\{Y, C O A, r\}}^{A^{1-\sigma} C O A}+\left(1-\theta_{i r}^{C O A}\right)\left(\prod_{j \in L Q} p_{Y j r}^{A^{\beta} j i r}\right)^{1-\sigma_{E L E}}\right]^{\frac{1-\sigma_{E L E}}{1-\sigma_{C O A}}}\right\}^{\frac{1}{1-\sigma_{E L E}}}=0$

3. Energy aggregate for electricity sector:

$\prod_{i r}^{E}=p_{i r}^{E}-\prod_{j \in\{G A S, O I L, C O A\}} p_{Y j r}^{A^{\beta_{j j r}}}=0$

4. Armington aggregate: 
$\Pi_{d i r}^{A}=p_{d i r}^{A}-\left[\left(\theta_{d i r}^{A} p_{i r}^{1-\sigma_{A}}+\left(1-\theta_{d i r}^{A}\right) p_{i r}^{M^{1-\sigma_{A}}}\right)^{\frac{1}{1-\sigma_{A}}}+t_{r}^{C O 2} a_{d i r}^{C O 2}\right]=0$

5. Aggregate imports across import regions:

$\Pi_{i r}^{M}=p_{i r}^{M}-\left(\sum_{s} \theta_{i s r}^{M} p_{i s}^{l-\sigma_{M}}\right)^{\frac{1}{l-\sigma_{M}}}=0$

6. Investment:

$\Pi_{r}^{I}=p_{r}^{I}-\sum_{i} \theta_{i r}^{I} p_{\text {Iir }}^{A}=0$

7. Public good production:

$\prod_{r}^{G}=p_{r}^{G}-\sum_{i} \theta_{i r}^{G} p_{G i r}^{A}=0$

8. Household consumption demand:

$\left.\Pi_{r}^{C}=p_{r}^{C}-\left(\theta_{C r}^{E} p_{C r}^{E}{ }^{1-\sigma_{E C}}+\left(1-\theta_{C r}^{E}\right)\left[\prod_{i \notin E G} p_{C i r}^{A^{\gamma} i r}\right)\right]^{1-\sigma_{E C}}\right)^{\frac{1}{1-\sigma_{E C}}}=0$

9. Household energy demand:

$\prod_{C r}^{E}=p_{C r}^{E}-\left(\sum_{i \in E G}\left(\theta_{i C r}^{E} p_{C i r}^{A}{ }^{l-\sigma_{E C}}\right)\right)^{\frac{1}{l-\sigma_{E C}}}=0$ 


\section{A.2 Market Clearance Conditions}

10. Labor:

$\bar{L}_{r}=\sum_{i} Y_{i r} \frac{\partial \Pi_{i r}^{Y}}{\partial p l_{r}}$

11. Capital:

$\bar{K}_{r}=\sum_{i} Y_{i r} \frac{\partial \Pi_{i r}^{Y}}{\partial p k_{r}}$

12. Natural resources:

$\bar{Q}_{i r}=Y_{i r} \frac{\partial \prod_{i r}^{Y}}{\partial p q_{i r}} \quad i \in F F$

13. Output for domestic markets:

$Y_{i r} \frac{\partial \Pi_{i r}^{Y}}{\partial p_{i r}}=\sum_{d j} A_{d j r} \frac{\partial \prod_{d j r}^{A}}{\partial p_{i r}}$

14. Sector specific energy aggregate:

$E_{i r}=Y_{i r} \frac{\partial \prod_{i r}^{Y}}{\partial p_{i r}^{E}}$

15. Import aggregate:

$M_{i r}=\sum_{d} A_{d i r} \frac{\partial \prod_{d i r}^{A}}{\partial p_{i r}^{M}}$ 
16. Armington aggregate:

$A_{d i r}=\sum_{j} Y_{j r} \frac{\partial \Pi_{j r}^{Y}}{\partial p_{d i r}^{A}}+C_{r} \frac{\partial \Pi_{r}^{C}}{\partial p_{d i r}^{A}}+I_{r} \frac{\partial \Pi_{r}^{I}}{\partial p_{d i r}^{A}}+G_{r} \frac{\partial \Pi_{r}^{G}}{\partial p_{d i r}^{A}}$

17. Household consumption:

$C_{r} p_{r}^{C}=w_{r} \bar{L}_{r}+v_{r} \bar{K}_{r}+\sum_{j \in F F} q_{j r} \bar{Q}_{j r}+t_{r}^{C O 2} \overline{C O 2}_{r}-p_{r}^{G} \bar{G}_{r}-p_{r}^{I} \bar{I}_{r}+\bar{B}_{r}$

18. Aggregate household energy consumption:

$E_{C r}=C_{r} \frac{\partial \Pi_{r}^{C}}{\partial p_{C r}^{E}}$

19. Government output:

$\bar{G}_{r}=G_{r}$

20. Investment:

$\bar{I}_{r}=I_{r}$

21. Carbon emissions:

$\overline{C O 2}_{r}=\sum_{i} \sum_{d} A_{d i r} \frac{\partial \prod_{d i r}^{A}}{\partial p_{d i r}^{A}} a_{d i r}^{C O 2}$ 
Table A.1: $\quad$ Sets

\begin{tabular}{ll}
\hline$i$ & Sectors and goods \\
$j$ & Aliased with $i$ \\
$r$ & Regions \\
$s$ & Aliased with $r$ \\
$E G$ & Energy goods except for crude oil: coal, refined oil, gas and electricity \\
$F F$ & Primary fossil fuels: coal, crude oil and gas \\
$L Q$ & Liquid fuels: refined oil and gas \\
$d$ & Demand categories: $Y=$ intermediate, $C=$ household, $G=$ government, and $I=$ investment
\end{tabular}

Table A.2: Activity variables

$Y_{i r} \quad$ Production in sector $i$ and region $r$

$E_{i r} \quad$ Aggregate energy input in sector $i$ and region $r$

$M_{i r} \quad$ Aggregate imports of good $i$ and region $r$

$A_{d i r} \quad$ Armington aggregate for demand category $d$ of good $i$ in region $r$

$I_{r} \quad$ Aggregate investment in region $r$

$G_{r} \quad$ Aggregate public output in region $r$

$C_{r} \quad$ Aggregate household consumption in region $r$

$E_{C r} \quad$ Aggregate household energy consumption in region $r$ 
Table A.3: Price variables

$p_{i r} \quad$ Output price of good $i$ produced in region $r$ for domestic market

$p_{i r}^{E} \quad$ Price of aggregate energy in sector $i$ and region $r$

$p_{i r}^{M} \quad$ Import price aggregate for good $i$ imported to region $r$

$p_{d i r}^{A} \quad$ Price of Armington aggregate for demand category $d$ of good $i$ in region $r$

$p_{r}^{I} \quad$ Price of investment demand in region $r$

$p_{r}^{G} \quad$ Price of government demand in region $r$

$p_{r}^{C} \quad$ Price of aggregate household consumption in region $r$

$p_{C r}^{E} \quad$ Price of aggregate household energy consumption in region $r$

$p l_{r} \quad$ Wage rate in region $r$

$p k_{r} \quad$ Price of capital services in region $r$

$p q_{i r} \quad$ Rent to natural resources in region $r(i \in \mathrm{FF})$

$t_{r}^{\mathrm{CO} 2} \quad$ Price of $\mathrm{CO}_{2}$ permit in region $r$ 
Table A.4: Cost shares

$\theta_{j i r} \quad$ Share of intermediate good $j$ in total costs of sector $i$ and region $r(\mathrm{i} \notin \mathrm{FF})$

$\theta_{i r}^{K L E} \quad$ Share of KLE aggregate in total costs of sector $i$ and region $r(\mathrm{i} \notin \mathrm{FF})$

$\theta_{i r}^{K L} \quad$ Share of labor in KL aggregate of sector $i$ and region $r(\mathrm{i} \notin \mathrm{FF})$

$\theta_{i r}^{E} \quad$ Share of energy in the KLE aggregate of sector $i$ and region $r(\mathrm{i} \notin \mathrm{FF})$

$\theta_{i r}^{Q} \quad$ Share of natural resources in sector $i$ of region $r(\mathrm{i} \in \mathrm{FF})$

$\theta_{T i r}^{F F} \quad$ Share of $\operatorname{good} j(T=j)$ or labor $(T=L)$ in sector $i$ and region $r(\mathrm{i} \in \mathrm{FF})$

$\theta_{i r}^{C O A} \quad$ Share of coal in non-electric energy demand by sector $i$ in region $r(\mathrm{i} \notin \mathrm{FF})$

$\theta_{i r}^{E L E} \quad$ Share of electricity in energy demand by sector $i$ in region $r$

$\beta_{j i r} \quad$ Share of fossil fuel $j$ in fuel compositedemand by sector $i$ in region $r(i \notin \mathrm{FF})$

$\theta_{i s r}^{M} \quad$ Share of imports of good $i$ from region $s$ to region $r$

$\theta_{d i r}^{A} \quad$ Share of domestic variety $i$ in Armington aggregate for demand category $d$ in region $r$

$\theta_{i r}^{I} \quad$ Share of good $i$ in investment for region $r$

$\theta_{r}^{G} \quad$ Share of good $i$ in government demand in region $r$

$\theta_{C r}^{E} \quad$ Share of energy in aggregate household consumption in region $r$

$\gamma_{i r} \quad$ Share of non-energy good $i$ in non-energy household consumption demand in region $r$

$\boldsymbol{\theta}_{E L E, C, r}^{E} \quad$ Share of electricity in aggregate household energy consumption in region $r$

$\theta_{i C r}^{E} \quad$ Share of non-electric energy good $i$ in the non-electric household energy consumption in region $r$ 
Table A.5: Endowments and emissions coefficients

$\bar{L}_{r} \quad$ Aggregate labor endowment for region $r$

$\bar{K}_{r} \quad$ Aggregate capital endowment for region $r$

$\bar{Q}_{i r} \quad$ Endowment of natural resource $i$ for region $r(\mathrm{i} \in \mathrm{FF})$

$\bar{G}_{r} \quad$ Aggregate government demand in region $r$

$\bar{I}_{r} \quad$ Aggregate investment demand in region $r$

$\bar{B}_{r} \quad$ Balance of payment surplus in region r (note: $\sum_{r} \bar{B}_{r}=0$ )

$\overline{\mathrm{CO}_{2}}$ Endowment of carbon emission rights in region $r$

$a_{d i r}^{c a r b} \quad$ Carbon emissions coefficient for fossil fuel $i(i \in F F)$ in demand category $d$ of region $r$ 
Table A.6: Elasticities

\begin{tabular}{|c|c|c|}
\hline$\sigma_{K L}$ & Substitution between capital and labor in production & 0.5 \\
\hline$\sigma_{K L E}$ & Substitution between energy and value-added in production & 0.3 \\
\hline$\sigma_{E L E}$ & $\begin{array}{l}\text { Substitution between electricity and the non-electric energy } \\
\text { composite in production }\end{array}$ & 1 \\
\hline$\sigma_{C O A}$ & $\begin{array}{l}\text { Substitution between coal and the non-coal fossil fuel composite in } \\
\text { production (except fossil fuels) }\end{array}$ & 0.5 \\
\hline$\sigma_{F F}$ & $\begin{array}{l}\text { Substitution between natural resources and other inputs in fossil fuel } \\
\text { production calibrated consistently to exogenous supply elasticities }\end{array}$ & $\begin{array}{c}\mu_{\mathrm{COA}}=0.5 \mu_{\mathrm{CRU}}=1.0 \\
\mu_{\mathrm{GAS}}=1.0\end{array}$ \\
\hline & $\mu_{F F}$ & \\
\hline$\sigma_{M}$ & Substitution between imports from different regions & 8 \\
\hline$\sigma_{A}$ & Substitution between the import aggregate and the domestic input & 4 \\
\hline$\sigma_{E C}$ & $\begin{array}{l}\text { Substitution between energy goods in household energy } \\
\text { consumption }\end{array}$ & 0.5 \\
\hline
\end{tabular}

